P.L. Tan MBBS MMed (Anaes),

T.L. Lee MBBS MMed (Anaes) FFARACS,

W.A. Tweed MD FRCPC

\title{
Carbon dioxide absorption and gas exchange during pelvic laparoscopy
}

Twelve ASA physical status I-II patients undergoing pelvic laparoscopy for infertility were enrolled in a study to quantify the effects of $\mathrm{CO}_{2}$ insufflation and the Trendelenburg position on $\mathrm{CO}_{2}$ elimination and pulmonary gas exchange, and to determine the minute ventilation required to maintain normocapnia during $\mathrm{CO}_{2}$ insufflation. Measurements of $\mathrm{O}_{2}$ uptake $\left(\mathrm{VO}_{2}\right), \mathrm{CO}_{2}$ elimination $\left(\dot{V} \mathrm{CO}_{2}\right)$, minute ventilation $(\mathrm{VE}), \mathrm{FlO}_{2}$, and respiratory exchange ratio $(R Q)$ were made during three steady states: control $(C)$ taken after 15 min of normoventilation but before $\mathrm{CO}_{2}$ insufflation, after $15 \mathrm{~min}\left(L_{1}\right)$ and $30 \mathrm{~min}\left(L_{2}\right)$ of hyperventilation during $\mathrm{CO}_{2}$ insufflation. The $\mathrm{FIO}_{2}$ was controlled at 0.5 and arterial blood gases were used to calculate the oxygen tension-based indices of pulmonary gas exchange. After $15 \mathrm{~min}$ and $30 \mathrm{~min}$ of $\mathrm{CO}_{2}$ insufflation, the volume of $\mathrm{CO}_{2}$ absorbed from the peritoneal cavity was estimated at $42.1 \pm 5.1$ and $38.6 \pm 6.6(\mathrm{SEM}) \mathrm{ml} \cdot \mathrm{min}^{-1}$ respectively, increasing $\mathrm{CO}_{2}$ elimination through the lungs by about $30 \%$. Hyperventilation of the lungs by a $20-30 \%$ increase in minute ventilation maintained normocapnia. Despite the $\mathrm{CO}_{2}$ pneumoperitoneum and Trendelenburg position, there was no impairment of pulmonary oxygen exchange as estimated by $(\mathrm{A}-\mathrm{a}) \mathrm{DO} \mathrm{O}_{2}$. This study demonstrated that a $30 \%$ increase in minute ventilation, achieved by increasing tidal volume to more than $10 \mathrm{ml} \cdot \mathrm{kg}^{-1}$, is sufficient to eliminate the increased $\mathrm{CO}_{2}$ load and maintain normal pulmonary $\mathrm{O}_{2}$ exchange during pelvic laparoscopy.

Key words

ANAESTHESIA: diagnostic;

CARBON DIOXIDE: absorption, elimination, respiratory quotient;

SURGERY: laparoscopy;

VENTILATION: alveolar, tidal volume.

From the Department of Anaesthesia, National University

Hospital, National University of Singapore.

Address correspondence to: P.L. Tan, Department of

Anaesthesia, National University Hospital, Lower Kent Ridge

Road, Singapore 0511.

Accepted for publication 24th March, 1992.
Douze patientes de la classe ASA I ou II subissant une laparoscopie pelvienne pour infertilité ont été incluses dans une étude qui visait d'une part, à quantifier let effets conjoints de l'insufflation du $\mathrm{CO}_{2}$ et de la position de Trendelenbourg sur l'élimination du $\mathrm{CO}_{2}$ ainsi que sur les échanges gazeux pulmonaires, et d'autre part, de déterminer la ventilation requise pour maintenir une normocapnie pendant l'insufflation. Trois moments d'équilibre ont été déterminés pour faire des mesures de captation d'O $\mathrm{O}_{2}\left(\dot{V}_{2}\right)$, d'élimination de $\mathrm{CO}_{2}\left(\dot{\mathrm{V}} \mathrm{CO}_{2}\right)$, de ventilation minute ( $V E)$, de $\mathrm{FlO}_{2}$ et de quotient respiratoire $(R Q)$. Ces moments sont : 15 minutes après une ventilation normale et précédant l'insuffiation de $\mathrm{CO}_{2}(C) ; 15$ minutes $\left(L_{l}\right)$ et 30 minutes $\left(L_{2}\right)$ d'hyperventilation accompagnant l'insufflation du $\mathrm{CO}_{2}$. La FlO $\mathrm{O}_{2}$ maintenue à 0,5 et la mesure des gaz artériels ont permis de calculer les échanges pulmonaires dépendant des pressions partielles en $\mathrm{O}_{2}$. Quinze et 30 minutes apres l'insufflation du $\mathrm{CO}_{2}$, la quantité de $\mathrm{CO}_{2}$ absorbée par la cavité péritonéale a été évaluée successivement à $42,1 \pm 5,1 \mathrm{ml} \cdot \mathrm{min}^{-1}$ et à $38,6 \pm 6,6(S E M) \mathrm{ml} \cdot \mathrm{min}^{-1}$, entraînant une augmentation d'élimination pulmonaire de $30 \%$. Une augmentation de ventilation minute de 20 à $30 \%$ a permis de maintenir une normocapnie. Malgré la présence de $\mathrm{CO}_{2}$ dans le péritoine et la position de Trendelenbourg, il n'y a pas eu d'altération des échanges pulmonaires en $\mathrm{O}_{2}$ estimés par la $\mathrm{DO}_{2}(A-a)$. Cette étude prouve qu'une augmentation de ventilation-minute de $30 \%$, obtenue par l'augmentation du volume courant à plus de $10 \mathrm{ml} \cdot \mathrm{kg}^{-1}$ suffit pour éliminer le surplus de $\mathrm{CO}_{2}$ et maintenir des échanges respiratoires normaux en $\mathrm{O}_{2}$ pendant une laparoscopie pelvienne.

Laparoscopy for visualisation of the pelvic organs was described in the early 20 th century ${ }^{1}$ but its usefulness in gynaecological surgery was first recognized by Steptoe in $1964 .^{2}$ Today, laparoscopy has moved beyond the realm of pelvic surgery to include abdominal surgery (e.g., laparoscopic cholecystectomy, appendicectomy and vagotomy).

Laparoscopy for pelvic surgery introduces three major physiological alterations: ${ }^{3}$

1 Trendelenburg position: usually with a $30^{\circ}$ head-down tilt to allow better visualisation of the pelvic viscera. 
The Trendelenburg position causes cardio-vascular and gas exchange impairment.

$2 \mathrm{CO}_{2}$ pneumoperitoneum: this further increases abdominal pressure and exaggerates the $\dot{V}_{A} / \dot{Q}$ imbalance due to the Trendelenburg posture.

$3 \mathrm{CO}_{2}$ absorption: $\mathrm{CO}_{2}$ is absorbed transperitoneally and the combination of hypercapnia and alveolar hypoventilation can lead to cardiac arrhythmias and even cardiac arrest. $^{4}$

Desmond and Gordon ${ }^{5}$ demonstrated the superiority of controlled hyperventilation over spontaneous respiration or controlled normoventilation for maintaining normal $\mathrm{PCO}_{2}$. However, they did not quantify the amount of $\mathrm{CO}_{2}$ absorbed or the increase in ventilation needed to maintain normocapnia.

This clinical study was undertaken to quantify the $\mathrm{CO}_{2}$ absorption and the effects on gas exchange in patients undergoing laparoscopy with $\mathrm{CO}_{2}$ insufflation in the Trendelenburg position. We also determined the increase in minute ventilation necessary to maintain normocapnia during $\mathrm{CO}_{2}$ insufflation.

\section{Methods}

The protocol was approved by the Departmental and Institutional Ethics Review Committee. Verbal consent was given by the patients for the study and for cannulation of the radial artery.

The study sample was 12 young women (age $33.5 \pm 4.8$ yr, weight $57.7 \pm 10.2 \mathrm{~kg}$ ) of ASA physical status I and II undergoing laparoscopic examination for infertility under general endotracheal anaesthesia. Routine pre-anaesthetic work-up included history, physical examination and routine full blood count. Patients with a history of recent pulmonary disease, abnormal physical findings or who smoked were excluded from the study.

Most patients received midazolam premedication. Those who were not premedicated were day surgery cases. Total intravenous anaesthesia was used which was induced with propofol $2 \mathrm{mg} \cdot \mathrm{kg}^{-1}$; fentanyl $2-3 \mu \mathrm{g} \cdot \mathrm{kg}^{-1}$ and succinylcholine $1-2 \mathrm{mg} \cdot \mathrm{kg}^{-1}$ was used to facilitate tracheal intubation. Anaesthesia was maintained with a continuous propofol infusion $\left(6-10 \mathrm{mg} \cdot \mathrm{kg}^{-1} \cdot \mathrm{hr}^{-1}\right)$ and intermittent doses of fentanyl. Muscle paralysis was achieved with atracurium $0.3 \mathrm{mg} \cdot \mathrm{kg}^{-1}$ and controlled intermittent positive pressure ventilation (IPPV) with a Siemens $900 \mathrm{C}$ servo ventilation at a rate of ten per minute in the volumecontrolled mode. The anaesthetic circuit was a nonrebreathing system with a mixture of air $/ \mathrm{O}_{2}$ with a $\mathrm{FIO}_{2}$ of 0.5 .

All patients were placed in the supine Trendelenburg tilt with $\mathrm{CO}_{2}$ insufflated through a trocar passed into the peritoneal cavity. Prior to $\mathrm{CO}_{2}$ insufflation patients' lungs were ventilated with a minute volume of about $80 \mathrm{ml} \cdot \mathrm{kg}^{-1}$ (tidal volume set at $8 \mathrm{ml} \cdot \mathrm{kg}^{-1}$, respiratory rate of ten per minute), adjusted to maintain an end-tidal $\mathrm{CO}_{2}\left(\mathrm{FETCO}_{2}\right)$ of $5 \%$. During $\mathrm{CO}_{2}$ insufflation, the minute volume was increased to at least $100 \mathrm{ml} \cdot \mathrm{kg}^{-1}$ (tidal volume increased to $10 \mathrm{ml} \cdot \mathrm{kg}^{-1}$ with a respiratory rate kept at ten per minute) to maintain $\mathrm{FETCO}_{2}$ constant. Conventional ratio ventilation was used with inspiratory time of $2.5 \mathrm{sec}$, and an inspiratory pause of $1 \mathrm{sec}$.

There were three study periods. The first set of measurements control (C) was taken 15 min after IPPV was started and before $\mathrm{CO}_{2}$ insufflation. The second $\left(\mathrm{L}_{1}\right)$ and third $\left(\mathrm{L}_{2}\right)$ sets were taken 15 and $30 \mathrm{~min}$ after beginning $\mathrm{CO}_{2}$ insufflation.

Airway pressures were recorded from the ventilator and FeTCO ${ }_{2}$ from a Siemens $\mathrm{CO}_{2}$ analyzer Model 930. A Datex Deltatrac Metabolic Monitor was used to measure $\mathrm{O}_{2}$ uptake $\left(\dot{\mathrm{VO}}_{2}\right), \mathrm{CO}_{2}$ elimination $\left(\dot{\mathrm{V}}_{2} \mathrm{CO}_{2}\right)$, minute ventilation (VE), $\mathrm{FIO}_{2}$ and respiratory exchange ratio (RQ). Metabolic measurements were recorded at one-minute intervals and the final five measurements during each study period were averaged. At the end of each study period, an arterial blood sample was drawn from the indwelling radial artery cannula and analyzed immediately in a Nova Stat Profile Blood Gas analyzer. Heart rate (HR) was recorded from the ECG monitor and blood pressure (BP) by an automatic BP monitor (Dinamap) at threeminute intervals. All measuring instruments were properly calibrated. The $\mathrm{O}_{2}$ and the $\mathrm{CO}_{2}$ analyzer of the metabolic monitor were calibrated with medical grade calibration gas containing $5 \% \mathrm{CO}_{2}$ and $95 \% \mathrm{O}_{2}$ before each study.

Pulmonary gas exchange was assessed by calculating the alveolar-arterial $\mathrm{O}_{2}$ tension gradient $(\mathrm{A}-\mathrm{a}) \mathrm{DO}_{2}$ based on $\mathrm{FiO}_{2}$, temperature corrected $\mathrm{PaO}_{2}$ and calculated $\mathrm{PaO}_{2}$.

The alveolar $\mathrm{O}_{2}$ tension was calculated by the formula adopted by Pappenheimer et al. ${ }^{6}$

$\mathrm{PAO}_{2}=\mathrm{FrO}_{2}\left(\mathrm{~PB}-\mathrm{Pa}_{\mathrm{H}_{2} \mathrm{O}}\right)-\mathrm{PaCO}_{2}\left[\mathrm{FIO}_{2}+\frac{1-\mathrm{FIO}_{2}}{\mathrm{RQ}}\right]$

Since Singapore is at sea level, the barometric pressure (PB) was assumed to be $760 \mathrm{mmHg}$ and alveolar $\mathrm{H}_{2} \mathrm{O}$ vapour pressure to be $47 \mathrm{mmHg}$. Day to day variation in barometric pressure in Singapore is less than $1 \%$ according to the Meteorological Service of Singapore.

The metabolic $\mathrm{CO}_{2}$ production was calculated from the measured $\mathrm{VO}_{2}$ by assuming that the ratio between metabolic carbon dioxide production and oxygen consumption remained constant and equal to the control RQ.

$\mathrm{RQ}\left(\right.$ Control-C) $\times \dot{\mathrm{VO}}_{2}=$ metabolic $\dot{\mathrm{VCO}}_{2}$.

Hence the amount of $\mathrm{CO}_{2}$ absorbed per $\mathrm{min}=$ measured $\dot{\mathrm{V}} \mathrm{CO}_{2}$ - metabolic $\dot{\mathrm{V}} \mathrm{CO}_{2}$, and the percentage increase in absorbed $\mathrm{CO}_{2}=$ absorbed $\mathrm{V} \mathrm{CO}_{2} /$ metabolic $\mathrm{VCO}_{2}$.

The alveolar $\mathrm{CO}_{2}$ fraction, $\mathrm{FACO}_{2}$ was calculated as follows:

The model for $\mathrm{CO}_{2}$ removal from the body describes 
TABLE I Conventional ratio ventilation: Mean \pm SEM $(n)$. Different study conditions with resultant haemodynamic, arterial blood gas analyses and tidal volume variables.

\begin{tabular}{lccc}
\hline & \multicolumn{1}{c}{$C(12)$} & \multicolumn{1}{l}{$L_{l}(12)$} & \multicolumn{1}{c}{$L_{2}(4)$} \\
\hline Tidal volume $\mathrm{VT} \mathrm{ml} \cdot \mathrm{kg}^{-1}$ & $8.6( \pm 0.3)$ & $10.4( \pm 0.2)^{*}$ & $10.8( \pm 0.2)^{*}$ \\
Temperature ${ }^{\circ} \mathrm{C}$ & $36.4( \pm 0.1)$ & $36.2( \pm 0.1)$ & $36.1( \pm 0.1)$ \\
Heart rate & $77.9( \pm 3.5)$ & $74.7( \pm 3.2)$ & $70.1( \pm 3.4)$ \\
Systolic $\mathrm{BP} \mathrm{mmHg}$ & $125.9( \pm 4.1)$ & $132.3( \pm 3.3)$ & $130.3( \pm 4.5)$ \\
Diastolic BP mmHg & $71.1( \pm 2.5)$ & $74.6( \pm 2.2)$ & $73.3( \pm 5.2)$ \\
$\mathrm{pH}$ & $7.34( \pm 0.01)$ & $7.34( \pm 0.01)$ & $7.34( \pm 0.02)$ \\
$\mathrm{PaCO}_{2} \mathrm{mmHg}^{\mathrm{PaO}} \mathrm{mmHg}^{2}$ & $42.3( \pm 1.0)$ & $42.1( \pm 1.1)$ & $43.0( \pm 1.0)$ \\
Base excess & $227.0( \pm 19.6)$ & $236.4( \pm 14.1)$ & $241.4( \pm 22.6)$ \\
\hline
\end{tabular}

$* P<0.01$ compared with $\mathrm{C}$.

TABLE II Pulmonary ventilation and gas exchange (mean \pm SEM). Different study conditions with resultant pulmonary ventilation and gas exchange variables. Metabolic $\mathrm{CO}_{2}$ and absorbed $\mathrm{CO}_{2}$ - see text for further details.

\begin{tabular}{lccc}
\hline & $C$ & $L_{1}$ & \multicolumn{1}{l}{$L_{2}$} \\
\hline $\mathrm{V} \mathrm{CO}_{2} \mathrm{ml} \cdot \mathrm{min}^{-1}$ & $146.0( \pm 5.9)$ & $183.3( \pm 5.0)^{*}$ & $172.0( \pm 6.2)^{*}$ \\
$\mathrm{VO} \mathrm{ml}_{2} \cdot \mathrm{min}^{-1}$ & $168.9( \pm 3.8)$ & $164.1( \pm 5.3)$ & $153.8( \pm 10.3)$ \\
$\mathrm{RQ}$ & $0.86( \pm 0.2)$ & $1.12( \pm 0.2)^{*}$ & $1.13( \pm 0.04)^{*}$ \\
$\mathrm{VA} \mathrm{ml} \cdot \mathrm{kg}^{-1}$ & $3.12( \pm 0.13)$ & $4.05( \pm 0.19)^{*}$ & $3.68( \pm 0.13)^{*}$ \\
$\mathrm{VD} / \mathrm{VT}$ & $0.32( \pm 0.2)$ & $0.31( \pm 0.1)$ & $0.32( \pm 0.02)$ \\
$(\mathrm{A}-\mathrm{a}) \mathrm{DO}_{2} \mathrm{mmHg}$ & $72.9( \pm 16.1)$ & $72.0( \pm 11.9)$ & $73.2( \pm 21.2)$ \\
Metabolic $\mathrm{CO}_{2}$ & $141.1( \pm 5.2)$ & $141.2( \pm 6.6)$ & $133.3( \pm 9.9)$ \\
Absorbed $\mathrm{CO}_{2}$ & - & $42.1( \pm 5.1)$ & $38.6( \pm 6.6)$ \\
$\% \uparrow \mathrm{CO}_{2}$ absorbed & - & $30 \%$ & $29 \%$ \\
$\% \uparrow(\mathrm{VA})$ & - & $30 \%$ & $28 \%$ \\
\hline
\end{tabular}

$* P<0.01$ compared with $\mathrm{C}$.

$\mathrm{VO}_{2}$ as a function of alveolar ventilation (VA) and alveolar $\mathrm{CO}_{2}$ concentration $\left(\mathrm{FACO}_{2}\right)$ :

$$
\dot{\mathrm{V}} \mathrm{CO}_{2}=\mathrm{VA} \cdot \mathrm{FACO}_{2} \quad \text { (Eq. 1) }
$$

The alveolar $\mathrm{CO}_{2}$ concentration can be estimated to be equal to the arterial $\mathrm{CO}_{2}$ concentration and the equation written as:

$\dot{\mathrm{V}} \mathrm{CO}_{2}=\mathrm{k}_{2} \cdot \mathrm{VA} \cdot \mathrm{PaCO}_{2}$

where $\mathrm{k}_{2}$ is a constant that converts arterial $\mathrm{CO}_{2}$ partial pressure $\left(\mathrm{PaCO}_{2}\right)$ to $\mathrm{CO}_{2}$ concentration and the $\mathrm{VCO}_{2}$ to standard pressure $(760 \mathrm{mmHg})$ dry gas. When $\mathrm{VA}_{\mathrm{A}}$ is given in $\mathrm{L} \cdot \mathrm{min}^{-1}$, body temperature $\left(37^{\circ} \mathrm{C}\right)$ and fully saturated with water vapour, and $\mathrm{PaCO}_{2}$ in $\mathrm{kPa}, \mathrm{k}_{2}=8.16$.

From equation 1 and 2 combined,

$\mathrm{VA} \cdot \mathrm{FaCO}_{2}=\mathrm{k}_{2} \cdot \mathrm{VA} \cdot \mathrm{PaCO}_{2}$

Therefore

$\mathrm{FaCO}_{2}=\mathrm{k}_{2} \cdot \mathrm{PaCO}_{2}$

$\% \mathrm{FACO}_{2}=\frac{\mathrm{PaCO}_{2}}{7.5} \times \frac{8.16}{1000}$

as $\mathrm{PaCO}_{2}$ is expressed in $\mathrm{kPa}$ when

$k_{2}=8.16$ and $\mathrm{FaCO}_{2}$ is expressed as a percentage fraction.

Effective alveolar ventilation (VA, BTPS) was then calculated as

$\mathrm{VA}=\dot{\mathrm{VCO}}_{2} / \mathrm{FACO}_{2}, \mathrm{~L} \cdot \mathrm{min}^{-1}(\mathrm{BTPS})$

Physiological dead space

$\mathrm{VD}=\mathrm{VE}-\mathrm{VA}$ (BTPS)

Physiological dead space to tidal volume ratio:

$\frac{\mathrm{VD}}{\mathrm{VT}}=1-\frac{\mathrm{VA}}{\mathrm{VE}}$

Measured and calculated variables from the three different study periods were compared by ANOVA. Two sample comparisons were by non-parametric tests: Wilcoxon signed rank test for paired data and the MannWhitney $\mathrm{U}$ test for unpaired data.

\section{Results}

The vital signs (BP and HR), temperature, and arterial blood gases were stable throughout with no significant changes from the base-line values (Table I).

Gas exchange and ventilatory data for the three measurement periods is presented in Table II. During the control (C) measurement, tidal volume was $8.6 \pm 0.3$ 


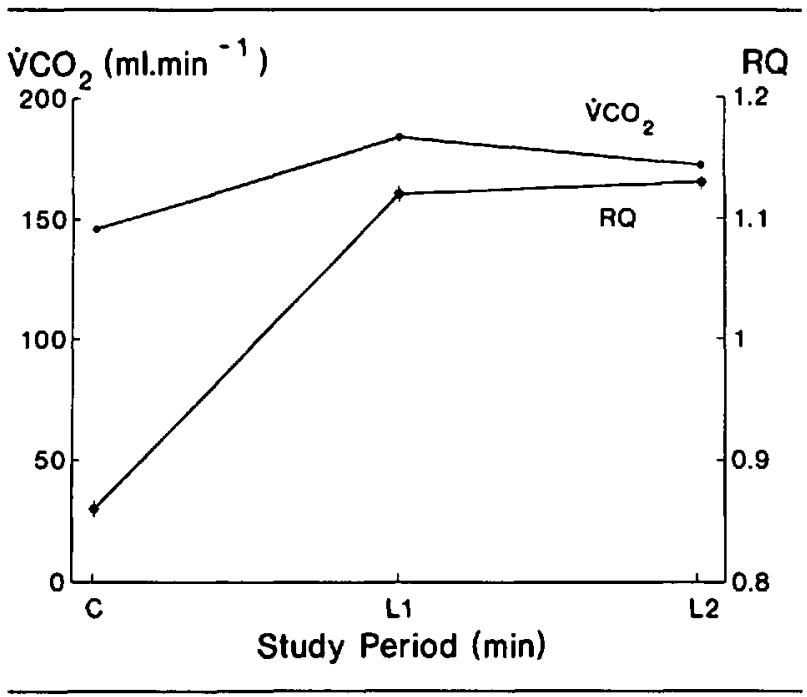

FIGURE Effects of time on $\mathrm{VCO}_{2}$ and $\mathrm{RQ}$.

$\mathrm{ml} \cdot \mathrm{kg}^{-1}$ and was increased to $10.4 \pm 0.2$ and $10.8 \pm 0.2$ $\mathrm{ml} \cdot \mathrm{kg}^{-1}$ at $\mathrm{L}_{1}$ and $\mathrm{L}_{2}$, during $\mathrm{CO}_{2}$ insufflation. Respiratory rate was held constant. Both $\dot{\mathrm{VCO}}_{2}$ and $\mathrm{RQ}$ were significantly increased at $\mathrm{L}_{1}$ and $\mathrm{L}_{2}$, reflecting an increased $\mathrm{CO}_{2}$ load presented to the lungs due to $\mathrm{CO}_{2}$ absorption from the peritoneal cavity. The calculated rate of absorption of $\mathrm{CO}_{2}$ at $\mathrm{L}_{1}$ and $\mathrm{L}_{2}$ was $42.1 \pm 5.1$ and $38.7 \pm 6.6$ $\mathrm{ml} \cdot \mathrm{min}^{-1}$ respectively. Arterial $\mathrm{PaCO}_{2}$ was maintained constant by an increase in effective alveolar ventilation estimated as 30 and $18 \%$ during $L_{1}$ and $L_{2}$ respectively.

There was no significant difference in gas exchange as assessed by the (A-a) $\mathrm{DO}_{2}$ between the $\mathrm{C}$ and the study periods $\mathrm{L}_{1}$ and $\mathrm{L}_{2}$ in spite of the $\mathrm{CO}_{2}$ pneumoperitoneum and the combined Trendelenburg lithotomy tilts (Table II). The physiological dead space to tidal volume ratio (VD/VT) also remained constant.

The effect of time on $\dot{\mathrm{V} C \mathrm{O}_{2}}$ and $\mathrm{RQ}$ are seen in the Figure. There was an increase in both $\dot{\mathrm{V}} \mathrm{CO}_{2}$ and $\mathrm{RQ}$ between $\mathrm{C}$ and $\mathrm{L}_{1}(P<0.001)$ but no further change between $L_{1}$ and $L_{2}$.

\section{Discussion}

Desmond and Gordon ${ }^{5}$ studied the effects of different ventilatory modes during laparoscopy, comparing spontaneous respiration with controlled normoventilation and with hyperventilation. They used a general anaesthetic with nitrous oxide and halothane for the spontaneously breathing group and added curare for controlled ventilation. Arterial blood was sampled and expired gases collected in a Douglas bag before and after the insufflation of $\mathrm{CO}_{2}$. They concluded that spontaneous respiration was dangerous because the large pneumoperitoneum with the steep Trendelenburg tilt and splinted diaphragm led to hypoventilation and hypercapnia and advocated routine hyperventilation to remove the excess $\mathrm{CO}_{2}$. However, they did not quantify the excess $\mathrm{CO}_{2}$ load nor the level of ventilation required to maintain normocapnia.

Our study was done using a total intravenous anaesthetic technique and an air- $\mathrm{O}_{2}$ mixture so as to eliminate the effect of nitrous oxide on the infra-red $\mathrm{CO}_{2}$ sensor in the Datex Metabolic Monitor. Inhalational agents were also omitted as they can affect the flow measurement. The Servo 900 C ventilator completely separates the inspiratory and expiratory gases, and is necessary for accurate collection of the expired gases. The performance of the Datex Deltatrac metabolic monitor has been validated recently. ${ }^{9}$

We demonstrated a $30 \%$ increase in $\mathrm{CO}_{2}$ load due to $\mathrm{CO}_{2}$ absorption from the peritoneal cavity. This required a $30 \%$ increase in alveolar ventilation to maintain normocapnia. The volume of $\mathrm{CO}_{2}$ absorbed appeared to reach a plateau and there was no further increase between 15 and 30 min. Rapid uptake of $\mathrm{CO}_{2}$ is due to the highly diffusible nature of $\mathrm{CO}_{2}$, but other factors such as the splanchnic circulation, the concentration gradient between the peritoneal cavity and the venous blood, and the amount of venous shunting in the splanchnic vascular bed also play a role. $\dot{V} A / \dot{Q}$ shunting in the lung has less effect on $\mathrm{CO}_{2}$ than on the less soluble gases like $\mathrm{N}_{2} \mathrm{O}$ and $\mathrm{O}_{2}$, so that $\dot{\mathrm{V}}_{\mathrm{A}} / \mathrm{Q}$ mismatching in the lungs during anaesthesia would have less effect on $\mathrm{PaCO}_{2}$.

The plateau in the $\mathrm{CO}_{2}$ elimination curve between 15 and $30 \mathrm{~min}$, in conjunction with constant levels of $\mathrm{PaCO}_{2}$, suggests that the excess $\mathrm{CO}_{2}$ absorbed from the peritoneal cavity had reached equilibrium with that removed by the increase in alveolar ventilation.

It has been shown that the well-known impairment gas exchange during anaesthesia is, to a large extent, attributable to early formation of atelectasis which in turn produces shunt. ${ }^{10}$ This impairment of gas exchange is much improved with Continuous Positive Pressure Ventilation $^{11}$ and Positive End Expiratory Pressure. ${ }^{12}$ In the present study we expected that the increased intraabdominal pressure due to the $\mathrm{CO}_{2}$ peritoneum and Trendelenburg tilt would worsen the cephalad shift of the diaphragm and the resultant compression atelectasis and pulmonary venous shunting caused by anaesthesia. However, we found no significant deterioration of pulmonary $\mathrm{O}_{2}$ exchange after $\mathrm{CO}_{2}$ insufflation and the Trendelenburg-lithotomy tilt. The reasons, we believe, are that the patients were young, non-obese and healthy, and that high tidal volume ventilation (there was a $30 \%$ increase in VT) had a protective effect.

In conclusion, this study demonstrated that during pelvic laparoscopy there was a rapid rise of about $30 \%$ in the $\mathrm{CO}_{2}$ load eliminated by the lungs. This quickly reached a plateau and could be compensated for by hyperventilation of the lungs with a $30 \%$ increase in minute ventilation. 


\section{Acknowledgements}

We gratefully acknowledge the support of the National University of Singapore and the National University Hospital.

\section{References}

1 Steptoe PC. Laparoscopy in gynaecology. London: E.S. Livingstone, 1967.

2 Steptoe PC. Gynaecological endoscopy: laparoscopy and culdoscopy. Journal of Obstetric and Gynaecology (British Commonwealth) 1965 ; 72 : 535-7.

3 Calverly $R K$, Jenkins $L C$. The anaesthetic management of pelvic laparoscopy. Can Anaesth Soc J, 1973; 20: 679-85.

4 Scott DB, Julian DG. Observations on cardiac arrhythmias during laparoscopy. BMJ 1972; 1: 411-3.

5 Desmond J, Gordon RA. Ventilation in patients anaesthetised for laparoscopy. Can Anaesth Soc J 1970; 17: 378-87.

6 Pappenheimer JR, Comroe JH, Cournand A, et al. Standardization of definitions and symbols in respiratory physiology. Fed Proc 1950; 9: 602-5.

7 Consolazio CF, Johnson RE, Pecora E. Physiological measurements of metabolic functions in man. New York; McGraw-Hill, 1964.

8 Kleiber $M$. The fire of life - an introduction to animal energetics. New York: John Wiley, 1961.

9 Takala J, Keinänen 0, Väisänen P, Kari A. Measurement gas exchange in intensive care: laboratory and clinical validation of a new device. Crit Care Med 1989; 17: 1041-7.

10 Hedenstierna $G$. Gas exchange during anaesthesia. $\mathrm{Br} \mathrm{J}$ Anaesth 1990; 64: 507-14.

11 Wyche MQ, TeichnerRL, Kallos T, Marshall BE, Smith TC. Effects of continuous positive pressure breathing on functional residual capacity and arterial oxygenation during intra-abdominal operations. Anesthesiology 1973; 38: 68-74.

12 Bindslev LG, Hedenstierna G, Santesson J, Gotlieb I, Carvalhas $A$. Ventilation-perfusion distribution during inhalational anaesthesia. Acta Anaesthesiol Scand 1981: 25: $360-71$. 